\title{
POLÍTICAS PÚBLICAS E BIBLIOTECAS NO BRASIL: CONHECENDO O SISTEMA NACIONAL DE BIBLIOTECAS PÚBLICAS - SNBP
}

\section{PUBLIC LIBRARY POLICIES IN BRAZIL: KNOWING THE SISTEMA NACIONAL DE BIBLIOTECAS PÚBLICAS - SNBP}

Elisabete Gonçalves Souza

\begin{abstract}
RESUMO
Introdução: discute políticas para as bibliotecas públicas no Brasil tendo como objeto de análise o Sistema Nacional de Bibliotecas Públicas (SNBP), que presta assessoria técnica às bibliotecas municipais, atuando de forma coordenada com o Sistema Estadual de Bibliotecas Públicas. Objetivo: conhecer com o SNBP foi instituído, seus objetivos, sua estrutura, atividades e o tipo de relação institucional que manteve com os órgãos com os quais esteve vinculado desde sua criação em 1992. Metodologia: pesquisa do tipo exploratória pautada em revisão de literatura, além de consultas a documentos legais relacionados com a temática. Resultados: relaciona as ações do SNBP com as políticas públicas para a área de cultura, como o Plano Nacional de Cultura e o Plano Nacional do Livro e Leitura, além de ações correlatas ligadas ao Programa Mais Livro; discute o papel político do SNPB e seu grau de ingerência sobre as ações que coordena. Conclusão: os anos de subordinação do SNBP à Fundação Biblioteca Nacional (FBN) minaram sua capacidade de atuar efetivamente no fortalecimento das bibliotecas públicas, como órgão planejador das ações e não apenas assessor e/ou executor das mesmas. Em 2014, a entidade passou a ser um órgão do Ministério da Cultura (MinC), mas não alcançou a autonomia desejada, além de ter sua ação e investimentos reduzidos. Sua situação tornou-se mais frágil em $2019 \mathrm{com}$ a extinção do MinC.
\end{abstract}

Descritores: Bibliotecas públicas. Políticas públicas. Sistema Nacional de Bibliotecas Públicas (Brasil).

\section{INTRODUÇÃO}

As bibliotecas públicas são equipamentos culturais que têm uma função social bem definida: garantir a todos os cidadãos o acesso à informação e à

a Doutora em História e Filosofia da Educação Brasileira pela Universidade Estadual de Campinas (Unicamp). Professora do Departamento de Ciência da Informação da Universidade Federal Fluminense (UFF). E-mail: elisabetes.souza@gmail.com. 
produção de conhecimentos. Essa condição é destacada na introdução do Manifesto IFLA/UNESCO (1994) que as define como um direito fundamental para o desenvolvimento da sociedade e do indivíduo.

\begin{abstract}
A participação construtiva e o desenvolvimento da democracia dependem tanto de uma educação satisfatória, como de um acesso livre e sem limites ao conhecimento, ao pensamento, à cultura e à informação [...] A biblioteca pública - porta de acesso local ao conhecimento - fornece as condições básicas para uma aprendizagem contínua, para uma tomada de decisão independente e para o desenvolvimento cultural dos indivíduos e dos grupos sociais. (IFLA/UNESCO, 1994, p. 1)
\end{abstract}

O Manifesto da IFLA/UNESCO sobre Bibliotecas Públicas é considerado um marco regulatório para os países signatários, como o Brasil, pois, "[...] para além da tipologia da área, a biblioteca pública é também caracterizada pelas suas relações entre estado e sociedade civil, entre propriedade e regime jurídico público - são as chamadas bibliotecas públicas estaduais e municipais". (MACHADO; ELIAS JR; ACHILLES, 2014, p. 119).

Os serviços da biblioteca pública devem, em princípio, ser gratuitos. A biblioteca pública é da responsabilidade das autoridades locais e nacionais. Deve ser objeto de uma legislação específica e financiada pelos governos nacionais e locais. (IFLA/UNESCO, 1994, p. 2).

A política cultural vigente, expressa nas diretrizes do Plano Nacional de Cultura ( $P C N)$ destaca a igualdade e a plena oferta de condições para a expressão e fruição culturais, como parte de uma nova geração dos direitos humanos, devendo "[...] ser vista como parte constitutiva de um projeto global de desenvolvimento de um país" (BRASIL, 2008, p. 33). Nessa direção, entende as políticas de cultura como programa de Estado e não de governo, cabendo a ele e aos demais entes federados (estados e municípios e o distrito federal) "[...] assegurar a continuidade das políticas públicas de cultura, instituindo mecanismos duradouros de planejamento, validação, promoção e execução" (BRASIL, 2008, p. 31), incluindo a garantia das fontes de financiamento e os recursos.

Neste sentido, a biblioteca pública, enquanto um direito social e de cidadania, para cumprir dignamente seu papel deve ter uma legislação específica. No Brasil, não temos um plano setorial para estas instituições, elas fazem parte de um plano que envolve a questão dos livros e da leitura, como 
ocorreu com a institucionalização, em 2006, do Plano Nacional do Livro e Leitura (PNLL).

Contudo, desde 1992, o Sistema Nacional de Bibliotecas Públicas (SNBP) vem assumindo essas responsabilidades. Mas, como veremos a seguir, ele possui pouca autonomia para planejar suas ações ou deliberar sobre as que the são atribuídas, tornando-se, na maioria, das vezes, apenas um executor de programas de fomento ao livro, à leitura e difusão da literatura, conforme as ações previstas nos quatro eixos do PNLL.

A centralidade das discussões em torno do acesso ao livro minimiza o papel da biblioteca pública como instituição social. Como se bastasse o gestor público ceder um espaço e comprar livros para ser ter uma biblioteca. No Brasil, essa visão funcionalista ainda prevalece e se expressa na maioria das políticas públicas para a área em detrimento de debates sobre a dimensão social, política e cultural que cerca a instituição. Conforme ressaltam Machado, Elias Júnior e Achilles (2014, p. 119) as bibliotecas públicas, não são

[...] espaços vazios nos quais indivíduos e coisas (registros gráficos do conhecimento, em particular) são alocados para atender a determinadas funções que a elas são atribuídas, mas o resultado de um conjunto de relações entre elementos (sujeitos e objetos) que conformam uma espécie de configuração, repleta de conflitos e tensões, em que os papéis atribuídos a biblioteca pública, enquanto uma instituição social, e as apropriações que os diversos sujeitos fazem desses espaços estão em constante diálogo. (MACHADO; ELIAS JUNIOR; ACHILLES, 2014, p. 119).

Para trazer à tona essa discussão e colocá-la no centro dos debates sobre as políticas públicas, o presente artigo partiu da seguinte questão: Qual o grau de ingerência do SNBP nas e sobre essas políticas públicas que coordena? Para respondê-la foi feita revisão de literatura, além de consultas a documentos legais relacionados com a temática. A busca de documentos diretamente relacionados às atividades do SNBP, como os seus relatórios anuais, não foi possível de ser realizada, pois seus links estão quebrados. Para compensar a falta de acesso a essas fontes consultamos os relatórios da Fundação Biblioteca Nacional, órgão ao qual o SNBP esteve vinculado até agosto de 2014, quando foi transferido para Brasília. 


\section{POLÍTICAS PÚBLICAS E BIBLIOTECA NO BRASIL}

Conforme ressalta Teixeira (2002) políticas públicas são diretrizes e princípios norteadores de ação do poder público junto à sociedade. Elas envolvem regras e procedimentos, e mediações entre os atores sociais e o Estado. Nesse caso, são "[...] políticas explicitadas, sistematizadas ou formuladas em documentos (leis, programas, linhas de financiamentos) que orientam ações que normalmente envolvem aplicações de recursos públicos" (TEIXEIRA, 2002, p. 2).

As concepções de políticas públicas variam de acordo com a orientação política do Estado. Na maioria dos países do Ocidente a visão social-democrata é predominante, ainda que o montante de investimentos seja diferenciado de acordo com as áreas prioritárias indicadas pelo Estado. Geralmente as áreas de assistência social, saúde e educação são as que concentram grandes investimentos, especialmente em países em desenvolvimento, como o Brasil. Nessa direção, tais políticas objetivam:

[...] os benefícios sociais como proteção aos mais fracos, como compensação aos desajustes da supremacia do capital, o que, ao mesmo tempo, garante sua reprodução e legitimação; as políticas públicas têm o papel regulador das relações econômico-sociais, são constituídos fundos públicos para serem utilizados em investimentos em áreas estratégicas para o desenvolvimento e em programas sociais [...] (TEIXEIRA, 2002, p. 4).

$\mathrm{Na}$ perspectiva deste estudo, compreendem-se as políticas públicas, conforme Teixeira (2002) e Ferreira (2006), como estratégias que servem para mudanças sociais, cujo princípio norteador é a igualdade social. As constituições representam os instrumentos legais garantidores de acesso a direitos sociais e de cidadania. Os direitos operam como "[...] princípio regulador das práticas sociais, definindo regras das reciprocidades esperadas na vida em sociedade através da atribuição das obrigações e responsabilidades [...]" (TELLES, 1994, p. 92).

Políticas públicas visando ampliação do acesso a bens culturais geralmente ficam secundarizadas em países com grandes desigualdades sociais. No entanto, a forte ligação entre educação e cultura vem fazendo com que o Estado brasileiro reveja esta questão e passe a se mobilizar para a confecção de planos nacionais e setoriais para a área de cultura. Essa 
preocupação reflete uma demanda da sociedade civil que, nas últimas décadas, organizada em movimentos sociais vem requerendo do Estado seus direitos constitucionais, entre eles o direito de usufruir de bens culturais, incluindo 0 acesso ao livro e à leitura por meio da ampliação da rede de bibliotecas públicas, ou delas se aproximando para organizar bibliotecas comunitárias.

No Brasil, o Plano Nacional de Cultura, previsto na Constituição Federal (BRASIL, 1988) desde a aprovação da Emenda Constitucional n.ำ 48, em 2005, começou a ser debatido somente no ano seguinte, quando foi elaborado Projeto de Lei n.ํ 6835/06 (BRASIL, 2006) visando à discussão de suas diretrizes e metas. O Projeto foi, então, encaminhado ao Congresso para apreciação junto à Comissão de Educação e Cultura da Câmara dos Deputados. As discussões consolidadas levaram à sua promulgação, sendo o Plano instituído pela Lei n.12.343, de 2 de dezembro de 2010 (BRASIL, 2010).

De acordo com a Lei (BRASIL, 2010), seu objetivo é "[...] orientar o desenvolvimento de programas, projetos e ações culturais que garantam a valorização, o reconhecimento, a promoção e a preservação da diversidade cultural existente no Brasil" (BRASIL, 2010, não paginado).

Como os demais Planos dessa natureza, o PNC tem uma duração de dez anos. Como ele foi aprovado em 2010, sua validade se dará até 2020.

Para que um Plano Nacional venha se efetivar é necessário a elaboração de planos a nível territorial, estadual e municipal, além de planos setoriais, voltados para os temas específicos (BRASIL, 2013). No âmbito das bibliotecas, desde a década de 1990 o governo federal, seja por meio do Ministério da Cultura ou da Educação, vem investindo em políticas específicas para a área, sendo a mais significativa e inovadora o Sistema Nacional de Bibliotecas Públicas (SISTEMA... 2019).

Segundo Machado (2008) o SNBP foi concebido visando à organização e a sistematização de um programa de apoio às bibliotecas públicas brasileiras, assim como criar uma rede de sustentação para as bibliotecas comunitárias. No entanto, sua subordinação à Fundação Biblioteca Nacional (FBN) “[...] amarrou sua estrutura, eliminando a possibilidade de agir de maneira autônoma minando 
sua capacidade e força para atuar efetivamente e de maneira contínua na dinamização e no fortalecimento desses espaços" (MACHADO, 2008, p. 79).

Para discutir os limites e as possibilidades das ações do SNBP enquanto política pública tomou-se como referência os estudos de Costa e Dagnino (2008). As autoras identificam três níveis de análise: Primeiramente identificar as instituições públicas, como são desenvolvidas e os atores que nestas se encontram em posição de maior evidência. Significa identificar as relações institucionais que elas e seus respectivos atores-chave mantêm entre si. No segundo nível, pesquisam-se as relações que se estabelecem "[...] entre esses atores-chave que representam os grupos de interesse existentes no interior de uma instituição e de grupos externos, situados em outras instituições públicas e em organizações privadas" (COSTA; DAGNINO, 2008, p. 57). O terceiro nível de análise é o que permitirá comparar a situação observada com o padrão (estrutura de poder e das regras de sua formação).

Neste artigo, tomaremos os três níveis de análise acima citados como o princípio norteador para analisar uma política pública voltada para o desenvolvimento das bibliotecas em nosso país: o SNBP, órgão criado em 1992, e que veio a substituir o Instituto Nacional do Livro (INL).

Atualmente o SNBP está vinculado à Secretaria Especial da Cultura do Ministério da Cidadania, mas durante 20 anos esteve atrelado à Biblioteca Nacional e mais recentemente ao Ministério da Cultura (MinC), extinto em janeiro de 2019. Uma história de subordinação administrativa que, na avaliação de especialistas da área, engessou as ações do Sistema inibindo sua preponderância enquanto órgão planejador, limitando suas atividades à assessoria técnica para os assuntos relacionados à instalação de bibliotecas públicas municipais e comunitárias, assim como o apoio para resolução de questões relacionadas à organização de acervos, formação de pessoal e gestão da informação.

\section{A INSTITUCIONALIZAÇÃO DO SNBP}


As origens SNBP estão presentes na história do INL'1. O instituto foi criado por meio do Decreto-lei n. 93, de 21 de dezembro de 1937 e esteve subordinado ao Ministério da Educação e Saúde Pública até 1953 quando, em função das mudanças na estrutura dos ministérios, passou a integrar o recém-criado Ministério da Educação e Cultura (TAVARES, 2014).

O INL era constituído por um Conselho de Orientação composto por três seções técnicas: Seção da Enciclopédia e do Dicionário; Seção de Publicações; Seção de Bibliotecas. A Seção de Bibliotecas tinha por objetivo organizar as políticas de distribuição de livros produzidos pela Seção de Publicações, de modo a ampliar os acervos das bibliotecas públicas do país, adquirir livros e distribuí-los gratuitamente, e oferecer assistência técnica às bibliotecas cadastradas (TAVARES, 2014; SIQUEIRA; MACHADO; LUCK, 2018). O INL realizou estas funções até 1992 quando, por meio do Decreto 520, de 13 de maio de 1992, foi substituído pelo SNBP.

\begin{abstract}
A Seção de Bibliotecas, como o Serviço Nacional de Bibliotecas já se configuravam como os embriões do atual SNBP e os bibliotecários, percebendo a importância e necessidade de formalizar tal situação, começavam a se movimentar e pressionar o governo a favor da criação do SNBP [...] (SIQUEIRA; MACHADO; LUCK, 2018, p. 31).
\end{abstract}

Segundo Machado (2010), a criação SNBP expressou uma preocupação por parte do estado com as bibliotecas públicas. O objetivo desta política, segunda a autora, era o fortalecimento das bibliotecas públicas por meio da "[...] implantação de um processo sistêmico baseado em ações voltadas para a interação e integração dessas bibliotecas em âmbito nacional" (BIBLIOTECA NACIONAL, 2006 apud MACHADO 2010, p. 100).

\footnotetext{
${ }^{1}$ Segundo Tavares (2104) Instituto Nacional do Livro (INL), foi criado por meio do decreto-lei n. 93, de 21 de dezembro de 1937, através da transferência do Instituto Cairu, que havia sido criado em janeiro daquele ano. Dentre suas funções constava: "[...] contribuir direta e eficientemente para o desenvolvimento cultural do país, por meio da política de edições de obras raras ou preciosas, consideradas de grande interesse para a cultura nacional, aumentar e melhorar a edição de livros no país, bem como facilitar a sua importação e incentivar a organização e manutenção de bibliotecas públicas em todo o território nacional" (TAVARES, 2014, p 164-165). O Instituto Nacional do Livro (1937-1991) ficava sediado nas dependências da Biblioteca Nacional, no Rio de Janeiro.
} 
Como desdobramento do SNBP criou-se, em cada estado da federação, um Sistema Estadual de Bibliotecas Públicas (SEBP)22, que tinha como objetivo articular as ações das diversas Bibliotecas Públicas Municipais. Dentre as ações de ambos os sistemas (nacional e o estadual) estava a implantação do Programa Livro Aberto, cuja proposta envolvia: a) implantação de bibliotecas em municípios que não as possuem; b) revitalização das já existentes; c) cadastro de bibliotecas públicas; d) capacitação e seminários e assessoria técnica para as bibliotecas cadastradas no sistema. Entre 2004 a 2011, período em que perdurou o Programa, foram criadas 1.705 novas bibliotecas e modernizadas 682 . (SISTEMA... 2019, não paginado).

Miranda (1979, p. 234) vê de forma positiva a constituição de Sistemas Estaduais de Bibliotecas, pois "[...] amplia-se a capacidade de seus serviços, facilitando o acesso à informação, barateando os seus custos, racionalizando suas tarefas e disciplinando o seu uso para um público mais amplo".

$\mathrm{Na}$ avaliação de Machado (2010), que também foi gestora do SNBP, sua concepção, enquanto política pública é inovadora "[...] no sentido de propor um sistema que pudesse agir de forma ramificada nesse país de dimensões continentais" (MACHADO, 2010, p. 100), mas a subordinação do SNBP, durante anos, à FBN impossibilitou seu desenvolvimento de forma autônoma. Para Machado (2010, p. 100), esta subordinação administrativa "[...] amarrou sua estrutura, eliminando a possibilidade de agir de maneira autônoma e, consequentemente, minando sua capacidade e força para atuar efetivamente e de maneira contínua na dinamização e no fortalecimento das bibliotecas públicas".

Apesar da pouca autonomia gerencial, o SNBP participou da construção do PNLL, instituído em 200633, integrando o Eixo 1 - democratização do acesso ao livro, cujas ações abaixo resumimos.

\footnotetext{
2 Segundo Tarapanoff e Suaiden (1995), o projeto de criação do SNBP foi aprovado pelo INL e, no ano de 1977, deu-se início a sua implementação. Logo em seguida, os Estados foram induzidos pelo governo federal a criar seus próprios sistemas, sendo o primeiro deles o SEBP do Maranhão, criado em 1980.

${ }^{3}$ BRASIL. Ministério da Educação. Portaria interministerial no 1.442, de 10 de agosto de 2006. [Institui o Plano Nacional do Livro e Leitura - PNLL]. Brasília, DF, Diário Oficial [da] República Federativa do Brasil, no 154 de 11/08/2006. Seção 1, p. 18/19. Disponível em: https://pesquisa.in.gov.br/imprensa/isp/visualiza/index.jsp?data=11/08/2006\&jornal=1\&pagina $=18 \&$ totalArquivos=128 Acesso em: 10 jun. 2019.
} 
Implantação de novas bibliotecas: Implantação de novas bibliotecas municipais e escolares (com acervos que atendam, pelo menos, aos mínimos recomendados pela Unesco, incluindo livros em braile, livros digitais, audiolivros etc., computadores conectados à Internet, jornais, revistas e outras publicações periódicas). Apoio à abertura de bibliotecas comunitárias (periferias urbanas, morros, hospitais, creches, igrejas, zonas rurais, clubes de serviços, ONGs etc.).

Fortalecimento da rede atual de bibliotecas: Fortalecimento e consolidação do Sistema Nacional de Bibliotecas Públicas, tornando-o realmente um sistema integrado, com níveis hierárquicos de bibliotecas e meios de circulação de acervos,

Conquista de novos espaços de leitura: Criação e apoio a salas de leitura, bibliotecas circulantes e "pontos de leitura" (ônibus, vans, peruas, trens, barcos etc.).

Distribuição de livros gratuita: Programas governamentais para distribuição de livros didáticos e não-didáticos para alunos nas escolas. Projetos de educação para a cidadania com livros (saúde, meio ambiente, trânsito, trabalho, juventude etc.).

Melhoria do acesso ao livro e a outras formas de expressão da leitura: Circuito nacional de feiras do livro. Co-edições de livros em braile, livros digitais e audiolivros para atender a portadores de necessidades especiais, em especial os deficientes visuais.

Incorporação e uso de tecnologias de informação e comunicação: Produção e desenvolvimento de tecnologias para a preservação de acervos, ampliação e difusão de bens culturais, como livros digitais, informatização de bibliotecas e bibliotecas digitais, entre outros. (BRASIL, 2010, p. 26-27). ${ }^{4}$

Com a institucionalização do PNLL, o SNBP passou a realizar ações conjuntas com outros órgãos, programas e projetos na área de leitura, literatura e bibliotecas, tais como o Programa Nacional de Incentivo à Leitura (PROLER), Agentes de Leitura, entre outros, e estimular a criação de Planos Estaduais e Municipais do Livro, Leitura e Bibliotecas. A inclusão do sistema aos parâmetros do PNLL fez do SNBP um órgão mais executor do que deliberativo das questões em torno das bibliotecas públicas.

Em 2007, por meio do Decreto Federal ํㅜ 6.226, foi instituído o Programa Mais Cultura, com o objetivo de:

I - ampliar o acesso aos bens e serviços culturais e meios necessários para a expressão simbólica, promovendo a autoestima, o sentimento

\footnotetext{
${ }^{4}$ O PNLL foi reeditado em 2010 e instituído em 1 de setembro de 2011 por meio do Decreto № 7.559 (BRASIL, 2011). A reedição de 2010 reforça os quatro eixos constituídos e acordados quando o Plano foi instituído pela primeira vez em 2006, a saber: I - a democratização do acesso ao livro; II - a formação de mediadores para o incentivo à leitura; III - a valorização institucional da leitura e o incremento de seu valor simbólico; e IV - o desenvolvimento da economia do livro como estímulo à produção intelectual e ao desenvolvimento da economia nacional.
} 
de pertencimento, a cidadania, o protagonismo social e a diversidade cultural;

II - qualificar o ambiente social das cidades e do meio rural, ampliando a oferta de equipamentos e dos meios de acesso à produção e à expressão cultural; e

III - gerar oportunidades de trabalho, emprego e renda para trabalhadores, micro, pequenos e médias empresas e empreendimentos da economia solidária do mercado cultural brasileiro. (BRASIL, 2007, não paginado)

Os objetivos acima constituem três linhas de ação, sendo que a primeira tem como diretriz "garantir o acesso dos brasileiros aos bens e serviços culturais" ação que muito se aproxima daquelas propostas pelo PNLL para o SNBP já que as bibliotecas são equipamentos culturais abertos às diversas manifestações e expressões artísticas e culturais.

Machado (2010) chama-nos a atenção para essa sobreposição de ações nas diretrizes dos Planos e Programas que constituem as políticas públicas. No caso da biblioteca pública, com a criação do PNLL, passou-se a ter, além do SNBP, outro órgão regulador para a área. O mesmo ocorreu com a criação do Programa Mais Cultura, cujo primeiro objetivo abarcava ações que se sobrepunham àquelas já realizadas pelo SNBP.

Segundo Costa e Dagnino (2008), para que se tenha uma boa gestão da coisa pública é fundamental que haja uma única agência de implementação de políticas públicas num determinado setor; que este setor [no SNBP] não dependa de outras ou, se outras agências estiverem envolvidas, que as relações de dependência sejam pequenas em número e importância" (COSTA DAGNINO, 2008, p. 123).

No caso do Programa Mais Cultura, Machado (2010) vê como positivo sua proposta entendendo-o como uma política pública que agregou à ação do SNBP. Cita que o Programa, por meio de sua linha de investimento, abriu vários editais para que os municípios pudessem pleitear recursos para as bibliotecas públicas e que essa iniciativa "[...] ampliou o conceito dos Pontos de Cultura e criou os Pontos de Leitura, que incorporaram as experiências das bibliotecas comunitárias" (MACHADO, 2010, p.105). De modo a esclarecer sobre as duas ações, explicamos a seguir que: 
Pontos de Cultura é uma ação do Programa Cultura Viva e articula todas as demais ações do Programa Mais Cultura (BRASIL, 2007). A ação se realiza por meio do estabelecimento de convênio entre o MinC e lideranças locais responsáveis por iniciativas culturais em comunidades espalhadas por todo 0 país. Os Pontos de Cultura "[...] são polos de articulação da cultura local, organizado de maneira a impulsionar as ações que já existem nas comunidades". (MACHADO, 2010, p. 105).

Pontos de Leitura envolvem ações na mesma linha dos Pontos de Cultura. No entanto, Machado (2010, p. 105) lamenta a falta de articulação com as bibliotecas públicas municipais, o que fortaleceria estes espaços públicos "[...] aproximando esferas que têm os mesmos ideais e que, de maneira sistêmica, terão melhores condições de enriquecer seus serviços, assim como sedimentar e multiplicar suas ações". Em sua crítica chama a atenção que:

Ao apoiar as iniciativas locais de forma deslocada das bibliotecas públicas, corremos o risco de mais uma vez fomentar o que Oliveira (1999) chama de "desnecessidade do público". Fazendo com que a sociedade assuma, de maneira inadequada, a responsabilidade por serviços públicos que são por essência de responsabilidade do Estado (MACHADO, 2010, p. 105).

Segundo o Mapa da Cultura (edição 2019) aplicativo disponibilizado no site Sistema Nacional de Informação e Indicadores Culturais (SNIIC), só na cidade do Rio de Janeiro existem cerca de 50 Pontos de Leitura.

A partir de 2010 as ações implementadas pelo SNBP passaram a ser planejadas de acordo com as metas estabelecidas do PNC. São 13 metas relacionadas às bibliotecas e, dentre elas, destacam-se: a Meta $32-100 \%$ dos municípios brasileiros com ao menos uma biblioteca pública em funcionamento e Meta $34-50 \%$ de bibliotecas públicas e museus modernizados (BRASIL, 2012).

Para realizar as ações previstas no PNLL e pelo Programa Mais Cultura, além das metas 32 e 34 do PNC, o SNBP possui uma estrutura organizacional constituída de uma Coordenação-Geral composta por três Coordenadorias, a saber: Coordenadoria de Apoio aos Sistemas Estaduais de Bibliotecas Públicas, Coordenadoria de Cadastro e Informação, e Coordenadoria de Acervo. Essa estrutura permaneceu até 2011. 
À Coordenação Geral do SNBP competia a supervisão das ações governamentais implementadas no âmbito federal, estadual e municipal; à Coordenadoria de Apoio aos Sistemas Estaduais de Bibliotecas Públicas competia a articulação com os sistemas estaduais na implementação das ações de implantação/modernização, capacitação e assessoria técnica, assim como planejar e executar o Encontro Nacional de Bibliotecas Públicas; à Coordenadoria de Cadastro e Informação cabia gerenciar o Cadastro Nacional de Bibliotecas Públicas e a Coordenadoria de Acervo "[...] era responsável pelo recebimento e distribuição para as bibliotecas públicas brasileiras dos livros e periódicos advindos da Lei Rouanet e das doações voluntárias realizadas por editores e autores" (SIQUEIRA; MACHADO; LUCK, 2018, p. 36-37).

Em 2010 o SNBP realizou, junto com a Diretoria do Livro, Leitura e Literatura (DLLL) do MinC, órgão ao qual à época estava vinculado, o I Censo Nacional das Bibliotecas Públicas Municipais com o objetivo de identificar o perfil destes equipamentos culturais no Brasil, e, desde então, "[...] vem trabalhando esses dados e validando as informações juntamente com os Sistemas Estaduais de Bibliotecas Públicas, com vistas a embasar as políticas, ações e os investimentos públicos na área de bibliotecas no país" (SNBP, 2019). Os dados coletados estão disponíveis para consulta no Sistema Nacional de Informação e Indicadores Culturais (SNIIC).

A partir de 2011, a denominação e as atribuições das Coordenadorias foram alteradas para: Coordenadoria de Relacionamento e Formação, Coordenadoria de Informação e Governança e Coordenadoria de Gestão Documental e Administrativa. Essas mudanças precederam outras mais radicais que ocorreriam nos anos seguintes, a saber.

Em 2012, por meio do Decreto № 7.748, de 06 de junho (BRASIL, 2012), a Diretoria de Livro, Leitura, Literatura e Bibliotecas do Ministério da Cultura foi incorporada à estrutura organizacional da FBN. Essa mudança fez como que o SNBP passasse a ser subordinado a essa Diretoria e não mais a presidência da FBN.

[...] considerando-se que a FBN já há muito assumia responsabilidades em torno das políticas públicas para o setor, sobretudo no que tange às bibliotecas públicas, por meio do SNBP (Sistema Nacional de 
Bibliotecas Públicas) e do incentivo à leitura, através do PROLER (Programa Nacional de Incentivo à Leitura). Nesse sentido, com 0 objetivo de buscar centralidade em um único órgão, tornou-se necessária a transferência da DLLL para a FBN, como forma de alcançar a unificação da formulação e execução das políticas públicas de livro, leitura, literatura e bibliotecas numa mesma unidade do Ministério da Cultura (FUNDAÇÃO... 2013, p.5).

Em 2014, por meio do Decreto n. 8297, de 15 de agosto (BRASIL, 2014), o SNBP foi transferido, juntamente com a Diretoria de Livro, Leitura, Literatura e Bibliotecas, para Brasília, sendo incorporado, a partir daquela data, à Secretaria Executiva do Ministério da Cultura.

No ano de 2014, a direção da Biblioteca tramitou o decreto que retirou de suas atividades as ações relacionadas ao estímulo da economia do livro, que retornaram ao Ministério da Cultura. Além dessas atividades, - SNBP (Sistema Nacional de Bibliotecas Públicas [...]e o Proler (Programa Nacional de Incentivo à Leitura) foram deslocados para a Diretoria de Livro, Leitura, Literatura e Bibliotecas (DLLLB), ligada à Secretaria Executiva do MinC (FUNDAÇÃO... 2015, p.. 26).

Em 2016, o Decreto no 8.837, de 17 de agosto $^{5}$ (BRASIL, 2016), estabeleceu uma nova estrutura no MinC, onde a DLLL se tornou Departamento de Livro, Leitura, Literatura e Bibliotecas (DLLLB), ficando vinculado a Secretaria da Cidadania e da Diversidade Cultural (SCDC), passando a SNBP a ser subordinado a esse Departamento.

Conforme ressaltam Siqueira, Machado e Luck (2018), a mudança do SNBP para o MinC era desejada, mas tem enfrentado problemas tais como: redução de sua estrutura organizacional, falta de investimentos e autonomia:

O SNBP, inicialmente, concentrava sua área de atuação em três
frentes: doação de acervo para as bibliotecas públicas, realização de
encontros voltados para a capacitação e troca de experiências entre os
profissionais que atuam na área de bibliotecas, e a prestação de
assessoria técnica às bibliotecas públicas brasileiras. No entanto, a
formulação das políticas públicas ficou na maior parte do tempo a cargo
da SLL, e posteriormente da DLLL, ambos subordinados diretamente
ao MinC e sediados em Brasília (SIQUEIRA; MACHADO; LUCK, 2018,
p.43).

Em 2018, com vista a fortalecer o SNBP foi instituída a Política Nacional de Leitura e Escrita (PNLE) como "[...] estratégia permanente para promover o livro, a leitura, a escrita, a literatura e as bibliotecas de acesso público no Brasil”

${ }^{5}$ O Decreto no 8.837 , de 17 de agosto de 2016, foi revogado pelo Decreto $n^{\circ}$ 9.674, de 2 de janeiro de 2019. 
(BRASIL, 2018) ${ }^{6}$. Mas por ser um programa novo ainda não temos como mensurar os resultados.

Em 2019, com extinção do Ministério da Cultura, o SNBP e o DLLLB foram transferidos para o Ministério da Cidadania, ficando subordinados às pastas de duas Secretarias: Cultura e Economia Criativa (SISTEMA... 2019). Com a extinção do MinC todo o cenário da política cultural do país sofreu transformação e o futuro do SNBP tornou-se mais fragilizado. Por isso, este artigo se encerra endossando as palavras de Siqueira, Machado e Luck (2018, p.43), que direcionam um apelo a toda a sociedade, em especial aos profissionais e pesquisadores da área de biblioteca para que o SNBP "[...] seja fortalecido para garantir-Ihe condições de atuar na valorização e melhoria dos espaços, acervos e serviços das bibliotecas públicas no país".

\section{CONCLUSÃO}

Desde sua criação o SNBP atua na implementação de ações para a qualificação das bibliotecas públicas trabalhando de maneira articulada com os estados, municípios e o Distrito Federal. Conforme informações recentes, o Sistema mantém parceria com 27 SEBPs desenvolvendo ações de estimulo ao livro, à leitura e às bibliotecas. Seu cadastro arrola "[...] 6057 bibliotecas públicas no Brasil, entre municipais, distritais, estaduais e federais, nos 26 estados e no Distrito Federal". (SISTEMA... 2019a, não paginado).

Ao sair da estrutura organizacional da FBN, vindo a integrar a administração direta do Ministério da Cultura em Brasília, pensava-se que o SNBP ganharia autonomia para fortalecer suas articulações nas diferentes esferas do governo, ampliando sua participação na construção das políticas públicas para as áreas do livro, da leitura e bibliotecas, mas isso não ocorreu, mantendo-se o órgão com suas características de assessoria técnica.

\footnotetext{
${ }^{6}$ Em junho de 2019, voltou à pauta de discussão do Senado Federal o PL 28/2015 que trata da criação da Política Nacional de Bibliotecas (BRASIL, 2015). O projeto foi encaminhado para Comissão de Assuntos Econômicos (CAE), que após análise e aprovação encaminhou o PL para Comissão de Educação, Cultura e Esporte (CE), cabendo a esta a decisão terminativa. Informações ver: https://www25.senado.leg.br/web/atividade/materias/-/materia/119687 Acesso em: 31 jul 2019.
} 
Para Machado (2010) os anos de subordinação do SNBP à FBN acabaram minando sua capacidade para atuar efetivamente e de maneira contínua na dinamização e no fortalecimento das bibliotecas públicas, como órgão planejador das ações e não apenas assessor e/ou executor das mesmas.

A mudança para Brasília, como órgão ligado diretamente ao MinC, não trouxe a autonomia desejada, pelo contrário, o SNBP teve sua ação e investimentos reduzidos. Situação essa mais fragilizada com a extinção do MinC em 2019.

Percebe-se que a busca por uma experiência autônoma não se concretizou, e isso dificulta as ações do SNBP de modo que a entidade tome a frente das questões sobre as bibliotecas públicas no Brasil, planejando e não só coordenando ou executando as ações.

Como vimos, um dos problemas enfrentados são as sobreposições de funções, como as designadas no PNLL e as executadas pelo SNBP que, no caso do Programa Mais Cultura, fez com que o Sistema passasse a apoiar os investimentos do Programa sem ter uma gerência sobre ele, como aconteceu com os Pontos de Leitura, criados sem articulação com as bibliotecas públicas municipais; sem um plano de avaliação dos impactos dos investimentos previstos, conforme ressaltou Machado (2010).

Em sua maioria, as bibliotecas públicas brasileiras não possuem recursos suficientes para se manter, para atualizar seus acervos, investir em tecnologia e muito menos na formação e qualificação de suas equipes, e é na direção de superar esse problema que atua o SNBP. Daí as críticas dos pesquisadores da área à postura passiva do Sistema diante dos Programas e Projetos que lhe são incumbidos de executar e gerir.

Apesar dos esforços empreendidos as políticas locais ainda estão emperradas, pois, de modo geral, estados e municípios, "[...] não estão preocupados com a biblioteca pública e não as veem como espaços estratégicos para o desenvolvimento local" (MACHADO, 2010, p. 108).

Inserida em um cenário político que não a vê como uma instituição social, que a desprestigia atribuindo-lhe minguados recursos financeiros, técnicos e humanos, a biblioteca pública se entrega às atividades instrumentais afastando- 
se de sua função social, cujas ações envolvem: a formação de leitores, a promoção do acesso à informação e o desenvolvimento da cultura local. Nessa direção, aponta-se para o SNBP o seguinte desafio: trazer as bibliotecas públicas para a cena institucional; universalizá-las enquanto direito público subjetivo, incluí-las nas políticas públicas em todas as esferas dos governos (local e nacional) de modo que, integradas às suas comunidades, possam contribuir de forma ativa para o desenvolvimento de seu território

\section{REFERÊNCIAS}

BRASIL. Decreto o 520 de 13 de maio de 1992. Institui o Sistema Nacional de Bibliotecas Públicas e dá outras providências. Diário Oficial [da] República Federativa do Brasil, Poder Executivo, Brasília, DF, 15 maio 1992. Disponível em: https://www2.camara.leg.br/legin/fed/decret/1992/decreto-520-13-maio1992-343159-normaatualizada-pe.pdf Acesso em: 19 jun. 2019.

BRASIL. Decreto no 6.226, de 4 de outubro de 2007. Institui o Programa Mais Cultura.Brasília, 2007.Diário Oficial [da] República Federativa do Brasil, poder Executivo, Brasília, DF,5 out. 2007.Disponível em: http://www.planalto.gov.br/ccivil_03/_Ato2007-2010/2007/Decreto/D6226.htm Acesso em: 20 jun. 2019.

BRASIL. Decreto № 7.559, de 1 de set. de 2011. Dispõe sobre o Plano Nacional do Livro e Leitura - PNLL e dá outras providências. Diário Oficial [da] República Federativa do Brasil, poder Executivo, Brasília, DF,1 set. 2011.Disponível em: https://pesquisa.in.gov.br/imprensa/jsp/visualiza/index.jsp?data=05/09/2011\&jor nal $=1$ \&pagina $=4 \&$ totalArquivos $=240$ Acesso em 10 ago .2020

BRASIL. Decreto no 7.748, de 06 de junho de 2012. Aprova o Estatuto e o Quadro Demonstrativo dos Cargos em Comissão e das Funções Gratificadas da Fundação Biblioteca Nacional. Brasília, DF: Poder Executivo, 2012. http://www.planalto.gov.br/ccivil_03/_Ato20112014/2012/Decreto/D7748impressao.htm Acesso 10 ago. 2020.

BRASIL. Decreto n. 8297, de 15 de agosto de 2014. Aprova o Estatuto e o Quadro Demonstrativo dos Cargos em Comissão e das Funções de Confiança da Fundação Biblioteca Nacional; altera os Anexos I e II ao Decreto ํㅜ 7.743, de 31 de maio de 2012. Brasília, DF: Poder Executivo, 2014. Disponível em: http://www.planalto.gov.br/ccivil_03/_Ato2011-2014/2014/Decreto/D8297.htm Acesso em 10 ago. 2020. 
BRASIL Decreto no 8.837, de 17 de agosto de 2016. Aprova a Estrutura Regimental e o Quadro Demonstrativo dos Cargos em Comissão e das Funções de Confiança do Ministério da Cultura... Brasília, DF: Poder Executivo, 2016. Disponível em: http://www.planalto.gov.br/ccivil_03/_Ato20152018/2016/Decreto/D8837impressao.htm Acesso em 10 ago. 2020.

BRASIL. Decreto oㅜ 9.674, de 2 de janeiro de 2019. Aprova a Estrutura Regimental e o Quadro Demonstrativo dos Cargos em Comissão e das Funções de Confiança do Ministério da Cidadania, remaneja cargos em comissão e funções de confiança.... Diário Oficial [da] República Federativa do Brasil, Poder Executivo, Brasília, DF, 2 jan. 2019. Disponível em: http://www.in.gov.br/materia/-

/asset_publisher/Kujrw0TZC2Mb/content/id/57759560 Acesso em: 22 jun. 2019.

BRASIL. Lei no 12.343, de 2 de dezembro de 2010. Institui o Plano Nacional de Cultura - PNC, cria o Sistema Nacional de Informações e Indicadores Culturais - SNIIC e dá outras providências. Brasília: Poder Executivo, 2010. Disponível em: http://www.planalto.gov.br/ccivil_03/_ato20072010/2010/lei/l12343.htm. Acesso em: 20 jun. 2019.

BRASIL. Lei no 13.696, de 12 de julho de 2018. Institui a Política Nacional de Leitura e Escrita. Brasília: Poder Executivo, 2018. Disponível em: http://www.planalto.gov.br/ccivil_03/_ato2015-2018/2018/Lei/L13696.htm. Acesso em: 10 jun. 2019.

BRASIL. Congresso. Câmara dos Deputados. Projeto de Lei n.o 6835/06. Aprova o Plano Nacional de Cultura. Brasília, DF: Câmara dos Deputados, 2006.

BRASIL. Constituição (1988). Emenda Constitucional no 48, de 10 e agosto de 2005. Acrescenta o § 3o ao art. 215 da Constituição Federal, instituindo o Plano Nacional de Cultura. Diário Oficial da União: Seção 1, Brasília, DF, p. 1, 11 ago. 2005. Disponível em:

http://www.planalto.gov.br/ccivil_03/constituicao/Emendas/Emc/emc48.htm\#: :t ext=Emenda\%20Constitucional\%20n\%C2\%BA\%2048\&text=Acrescenta\%200\% 20\%C2\%A7\%203\%C2\%BA\%20ao,FEDERAL\%2C\%20nos\%20termos\%20do\% 20art. Acesso 10 jul. 2019.

BRASIL. Ministério da Cultura. Como fazer um plano de cultura. Brasília, DF, MinC, Secretaria de Políticas Culturais, 2013. Disponível em:

http://www.cultura.pr.gov.br/arquivos/File/Como_fazer_um_plano_de_cultura.pd f Acesso em: 18 fev. 2019.

BRASIL. Ministério da Cultura. As metas do Plano Nacional de Cultura.

Brasília, DF: MinC, 2012. Disponível em:

http://www.fundacaocultural.ba.gov.br/colegiadossetoriais/As-Metas-do-Plano-

Nacional-de-Cultura.pdf. Acesso em: 17 fev. 2019. 
BRASIL. Ministério da Cultura. Plano Nacional de Cultura: diretrizes gerais. 2. ed. Brasília: DF: Ministério da Cultura, 2008.

BRASIL. Ministério da Cultura. Plano Nacional do Livro e Leitura. Edição atualizada. Brasília, DF: MinC, 2010.

COSTA, Greiner; DAGNINO, Renato (Org.). Gestão estratégica em políticas públicas. Rio de Janeiro: T. Mais Oito, 2008.

FERREIRA, Maria Mary. Políticas públicas de informação e políticas culturais: e as bibliotecas públicas para onde vão? TransInformação, Campinas, v. 8, n.2, p. 113-122, maio/ago., 2006.

FUNDAÇÃO BIBLIOTECA NACIONAL (Brasil). Relatório da gestão do exercício de 2012. Rio de Janeiro: FBN, 2013. Disponível em: https://www.bn.gov.br/sites/default/files/documentos/relatorio-gestao/ano2012/ano-2012-582.pdf Acesso em 18 jun. 2019.

FUNDAÇÃO BIBLIOTECA NACIONAL (Brasil). Relatório da gestão do exercício de 2014. Rio de Janeiro: FBN, 2015. Disponível em:

https://www.bn.gov.br/sites/default/files/documentos/institucionais/relatoriogestao/ano-2014/relatoriodegestaode2014fbnversaofinal0_0_0.pdf Acesso em 18 jun 2019

IFLA/UNESCO. Manifesto da IFLA/UNESCO sobre Bibliotecas Públicas. [online]. 1994. Disponível em: https://www.ifla.org/files/assets/publiclibraries/publications/PL-manifesto/pl-manifesto-pt.pdf. Acesso: 23 jun. 2019.

MACHADO, Elisa Campos. Bibliotecas comunitárias como prática social no Brasil. São Paulo, 2008. Tese (Doutorado em Ciência da Informação) - Escola de Comunicação e Artes, Universidade de São Paulo, São Paulo, 2008. Disponível em: https://www.teses.usp.br/teses/disponiveis/27/27151/tde07012009-172507/publico/Tese.pdf Acesso em: 10 jun 2019.

MACHADO, Elisa; ELIAS JÚNIOR, Alberto Calil; ACHILLES, Daniele. A biblioteca pública no espaço público: estratégias de mobilização cultural e atuação sócio-política do bibliotecário. Perspectivas em Ciência da Informação, Belo Horizonte, v.14, número especial, p.115-127, out./dez. 2014. Disponível em:

http://portaldeperiodicos.eci.ufmg.br/index.php/pci/article/view/2263/1521 Acesso em: 19 jun. 2019.

MACHADO, Elisa Campos. Análise de políticas públicas para bibliotecas no Brasil. InCID: R. Ci. Inf. e Doc., Ribeirão Preto, v. 1, n.1, p. 94-111, 2010. Disponível: http://www.revistas.usp.br/incid/article/view/42307/45978 Acesso em: 11 maio 2019. 
MIRANDA, Antônio. Considerações sobre o desenvolvimento de redes e sistemas de bibliotecas públicas no Brasil. Revista de Biblioteconomia de Brasília, v. 7, n. 2, jul./dez. 1979. Disponível em:

https://brapci.inf.br/_repositorio/2011/05/pdf_9b79cb995f_0016896.pdf Acesso em: 11 maio 2019.

SIQUEIRA, Bianca Lopes; MACHADO, Elisa Campos LÜCK, Esther Hermes. Trajetória e institucionalização do Sistema Nacional de Bibliotecas Públicas no Brasil. Revista Brasileira de Biblioteconomia e Documentação, São Paulo, v. 14, n. esp. 45 anos, 2018. Disponível em:

https://rbbd.febab.org.br/rbbd/article/view/1078 Acesso em 13 jun.2019.

SISTEMA NACIONAL DE BIBLIOTECAS PÚBLICAS (Brasil). Histórico, estrutura e atividades. [website], Brasília,2019. Disponível em:

http://snbp.cultura.gov.br/sobre/historico/. Acesso em: 21 jul. 2019.

SISTEMA NACIONAL DE BIBLIOTECAS PÚBLICAS (Brasil). Informações das bibliotecas públicas [website]. 2019a. Disponível em:

http://snbp.cultura.gov.br/bibliotecaspublicas/. Acesso em: 21 jul. 2019.

TARAPANOFF, Kira; SUAIDEN, Emir José. Planejamento estratégico de bibliotecas públicas no Brasil: histórico, crise e perspectivas. Revista de Biblioteconomia de Brasília, v. 19, n.2, p. 137-165, jul./dez., 1995.

TAVARES, Mariana Rodrigues. Editando a nação e escrevendo sua história: $O$ Instituto Nacional do Livro e as disputas editoriais entre 1937-1991, Aedos, Porto Alegre, n.15, v.6, jul./dez. 2014. Disponível em:

https://seer.ufrgs.br/index.php/aedos/article/view/45083 Acesso em: 18 jun 2019.

TEIXEIRA, Elenaldo Celso. Políticas Públicas: O papel das políticas públicas. Salvador: AATR-BA, 2002.

TELLES, Vera da Silva. Pobreza, movimentos sociais e cultura política: notas sobre as (difíceis) relações entre pobreza, direitos e democracia. In: DINIZ, Eli; LOPES, José Sergio, PRANDI, Reginaldo. (org.) O Brasil no rastro da crise: partidos, sindicatos, movimentos sociais, Estado, cidadania nos cursos dos anos 90. São Paulo: ANPOCS: HUCITEC, 1994. p. 225-243.

\title{
PUBLIC LIBRARY POLICIES IN BRAZIL: KNOWING THE SISTEMA NACIONAL DE BIBLIOTECA PUBLICAS- SNBP
}

\begin{abstract}
Introduction: discusses policies for public libraries in Brazil having as object of analysis the National System of Public Libraries (SNBP), which provides technical advice to municipal libraries, acting in coordination with the State System of Public Libraries. Objective: To get to know the SNBP was established, its objectives, its structure,
\end{abstract}


activities and the type of institutional relationship it has maintained with the organs with which it has been linked since its inception in 1992. Methodology: exploratory research based on literature review, as well as consultations on legal documents related to the subject. Results:it relates SNBP actions with public policies for the area of culture, such as the Plano National de Culture and the Plano Nacional do Livro e Leitura as well as related actions linked to the Programa Mais Livro; discusses the political role of the SNPB and its degree of interference with the actions it coordinates. Conclusion: SNBP's years of reporting to the Fundação Biblioteca Nacional (FBN) have undermined its ability to effectively strengthen public libraries as the action's planning body and not just their advisor and / or executor. In 2014, the entity became a body of the Ministry of Culture (MinC), but did not achieve the desired autonomy, besides having its action and investments reduced. His situation became more fragile in 2019 with the extinction of MinC.

Descriptors: Public libraries (Brasil). Public policy (Brasil). Sistema Nacional de Bibliotecas Públicas (Brasil).

\section{POLÍTICAS PÚBLICASY BIBLIOTECAS EN BRASIL: CONOCIENDO EL SISTEMA NACIONAL DE BIBLIOTECA PÚBLICAS - SNBP}

\section{RESUMEN}

Introducción: analiza las políticas para las bibliotecas públicas en Brasil que tienen como objeto de análisis el Sistema Nacional de Bibliotecas Públicas (SNBP), que brinda asesoramiento técnico a las bibliotecas municipales, actuando en coordinación con el Sistema Estatal de Bibliotecas Públicas. Objetivo: conocer el SNBP establecido, sus objetivos, su estructura, actividades y el tipo de relación institucional que ha mantenido con los órganos con los que se ha vinculado desde su creación en 1992. Metodología: investigación exploratoria basada en la revisión de literatura, así como consultas sobre documentos legales relacionados con el tema. Resultados: relaciona las acciones de SNBP con las políticas públicas para el área de cultura, como el Plan Nacional de Cultura y el Plano Nacional do Libro e Leitura, así como acciones relacionadas vinculadas al Programa Mais Livro; analiza el papel político del SNPB y su grado de interferencia con las acciones que coordina. Conclusión: Los años de SNBP de informar a la Fundação Biblioteca Nacional (FBN) han socavado su capacidad de fortalecer efectivamente las bibliotecas públicas como el organismo de planificación de la acción y no solo como su asesor y / o ejecutor. En 2014, la entidad se convirtió en un órgano del Ministerio de Cultura (MinC), pero no logró la autonomía deseada, además de reducir su acción e inversiones. Su situación se volvió más frágil en 2019 con la extinción de MinC.

Descriptores: Bibliotecas públicas. Políticas públicas. Sistema Nacional de Bibliotecas Públicas (Brasil).

Recebido em: 02.10.2019

Aceito em: 31.07. 2020 